\title{
Manejo sanitario de pollos de engorde en granjas de Cundinamarca, Colombia
}

\section{Health management of broiler chickens in Farms of Cundinamarca, Colombia}

\author{
Duarte Brito Diego Andrés ${ }^{1}$, Hernández Martínez María Cristina ${ }^{2}$ y \\ Bautista Perea Carlos Alberto ${ }^{3}$ \\ ${ }^{1}$ Médico Veterinario Zootecnista, Universidad de los Llanos, \\ ${ }^{2}$ Médico Veterinario Zootecnista, Docente Catedrática, Universidad de los Llanos y \\ ${ }^{3}$ Médico Veterinario, Empresa EMPOLLACOL S.A \\ chernandez@unillanos.edu.co
}

Recibido 20 de Febrero 2017, Aceptado 26 de Mayo 2017

\section{RESUMEN}

Este trabajo se realizó en el departamento de Cundinamarca, que tiene una humedad relativa anual entre 80 y $85 \%$, la temperatura media es de $24^{\circ} \mathrm{C}$ alcanzando algunas veces valores superiores a los $30^{\circ} \mathrm{C}$ y precipitación anual de 1500 a $2500 \mathrm{~mm}$, las 28 producciones avícolas con las cuales se trabajó, se encuentran principalmente ubicadas en los municipios de Madrid, Bituima, Villeta Albán y Cambao. Durante seis meses se llevaron a cabo labores de limpieza y desinfección en granjas donde se sacrificaban aves de 46 a 48 días de edad y para lo cual se destinó un periodo de vacío sanitario de la granja mínimo de 15 días. De acuerdo a los puntos anteriormente expuestos, fue de vital importancia conocer el estatus sanitario de la casa materna para instaurar los protocolos de inmunización animal, y teniendo en cuenta las condiciones de la vacuna, se realizaron procedimientos dependiendo de las especificaciones del laboratorio. Cada granja tenía una capacidad de tres a cuatro galpones, donde se albergaban entre 20.000 a 30.000 aves, para un total aproximado de 500.000 en todas las producciones, con ciclo de vacunación y revacunación si era necesario. Para esta labor se estableció una tabla en la cual se llevó a cabo la recolección de los datos, donde se especificó el número total de aves muertas por día, edad, hallazgos macroscópicos en granja, entre otros, con el fin de elaborar una tabla de distribución de frecuencias y así poder establecer una relación epidemiológica 
para cada predio, y de acuerdo a los resultados recomendar un plan de acción para mejorar los programas sanitarios y por tanto su efectividad, y así contribuir al mejoramiento del producto final. Los protocolos de limpieza y desinfección utilizados en las fincas productoras de pollos, se focalizan en dos eventos específicos, el reciclado y compostaje de la cama o su retiro total del galpón; si el caso era reciclado de la cama, el fin primordial fue la sanitización siendo el punto clave la completa desinfección, en particular este proceso se llevó a cabo con el mayor rigor posible. Cuando se implementaron estos procesos y métodos de prevención y manejo sanitario de las granjas se obtuvieron beneficios en cuanto a: capacitación de personal, identificación de puntos críticos de contagio, establecimiento de planes de vacunación de acuerdo a cada granja, para lo cual fueron importantes los resultados de las necropsias; todas estas acciones y procedimientos apuntaron a disminuir la intervención de los animales en pie, con el fin de evitar el estrés, disminuyendo en $5 \%$ las necropsias en seis meses.

Palabras clave: Sanidad, vacunación, producción avícola, patógenos.

\begin{abstract}
This work was carried out in the department of Cundinamarca, which has an annual relative humidity between 80 and $85 \%$, the average temperature is $24^{\circ} \mathrm{C}$ sometimes reaching values above $30^{\circ} \mathrm{C}$ and annual precipitation of 1500 to 2500 $\mathrm{mm}$, the 28 poultry farms with which it was worked, are mainly located in the municipalities of Madrid, Bituima, Villeta, Albán and Cambao. During six months, cleaning and disinfection were carried out on farms where birds 46 to 48 days old were slaughtered and for which it was intended a minimum sanitary period of the farm of 15 days. According to the above points, it was vital to know the health status of the maternal home to establish the animal immunization protocols, and taking into account the conditions of the vaccine, procedures were performed depending on the laboratory specifications. Each farm had a capacity of three to four sheds, where 20,000 to 30,000 birds were housed, for a total of approximately 500,000 in all productions, with vaccination and revaccination cycle if was necessary. For this work a table was established in which the collection of the data
\end{abstract}


was carried out, where the total number of dead birds per day was specified, age, macroscopic findings on farm, among others, with the purpose of elaborating a table of distribution of frequencies and thus be able to establish an epidemiological relationship for each farm, and according to the results recommend a plan of action to improve health programs and therefore their effectiveness, and thus contribute to the improvement of the final product. The protocols of cleaning and disinfection used in the farms producing chickens, are focused on two specific events, the recycling and composting of the bed or its total removal from the shed; if the case was recycled from the bed, the primary purpose was sanitization being the key point the complete disinfection, in particular this process was carried out with the greatest possible rigor. When these processes and prevention methods and sanitary management of the farms were implemented, benefits were obtained in terms of: training of personnel, identification of critical points of contagion, establishment of vaccination plans according to each farm, for which the results of necropsies were important; all these actions and procedures aimed to reduce the intervention of standing animals, in order to avoid stress, decreasing necropsies by $5 \%$ in six months.

Keywords: Health, vaccination, poultry production, pathogens.

\section{RESUMO}

Este trabalho foi feito no departamento de Cundinamarca, que tem uma humidade relativa anual entre 80 e $85 \%$, a temperatura média é de $24^{\circ} \mathrm{C}$ atingindo alguns vezes valores acima de $30^{\circ} \mathrm{C}$ e precipitação anual de 1500 a $2500 \mathrm{~mm}$, as 28 produções avícolas com as quais é trabalhou, estão localizados principalmente nos municípios de Madrid, Bituima, Villeta Albán e Cambao. Durante seis meses foram realizados trabalhos de limpeza e desinfecção em fazendas onde é sacrificaram aves de 46 a 48 dias de idade e para o qual foi alocado um período de vazio sanitário da fazenda mínimo de 15 dias. De acordo com pontos discutidos anteriormente, foi de vital importancia saber o estado de saúde da casa da mãe para estabelecer os protocolos de imunização animal, e tendo em conta as condições da vacina, foram realizados procedimentos dependendo das 
especificações do laboratório. Cada fazenda tinha uma capacidade de três a quatro galpões, onde são alojados entre 20.000 a 30.000 aves, com ciclo de vacinação e revacinação se era necessário. Para este trabalho estabeleceu-se uma tabela em a qual foi realizada a recolha de dados, onde foi especificado o número total de aves mortas por dia, idade, achados macroscópicos em fazenda, entre outros, com o fim de fazer uma tabela de distribuição de frequências e assim poder estabelecer uma ligação epidemiológica para cada site, e de acordo com os resultados recomendar um plano de ação para melhorar os programas de saúde e, portanto sua eficácia, e, assim, contribuir para a melhoria do produto final. Os protocolos de limpeza e desinfecção usados em explorações produtoras de galinhas, se concentram em dois eventos específicos, o reciclagem e compostagem da cama ou sua retirada total o galinheiro; se o caso era reciclado da cama, o objetivo principal foi a sanitização sendo o ponto-chave a desinfecção completa, em particular, este processo foi realizado com o máximo rigor possível. Quando foram implementados esses processos e métodos de prevenção foram obtidos benefícios em termos de: treinamento de pessoal, identificação dos pontos críticos de contágio, estabelecimento de planos de vacinação de acordo com cada fazenda, para o cual foram importantes os resultados da necropsia; todas essas ações e procedimentos apontaram para diminuir a intervenção dos animais vivos, com o fim de evitar o stress, diminuindo em $5 \%$ as necropsias em seis meses.

Palavras-chave: Saúde, imunização, produção de aves, patógenos.

\section{IMPORTANCIA DE LA SANIDAD EN LA PRODUCCIÓN DE POLLOS DE ENGORDE}

Con el vertiginoso desarrollo de la avicultura en el mundo, también crece al mismo paso, los problemas que la rodean, es por esto que en el área de la salud pública y la epidemiologia, reviste gran importancia, conocer y establecer los métodos que permitan prevenir y controlar la diseminación de enfermedades en las aves en producción, y aquellas enfermedades con posible riesgo zoonótico, generadoras de graves consecuencias en la población humana; claro ejemplo de ello, lo acontecido con el brote de influenza aviar $\mathrm{A} \mathrm{H}_{7} \mathrm{~N}_{9}$, transmitido a partir de palomas 
silvestres (Columba livia) y que llegó a causar el primer caso confirmado de contagio de este serotipo en humanos en Abril del 2013, en la ciudad de Beijing, China (Ortiz y Jiménez, 2013).

En el caso de enfermedades de interés comercial que afectan directamente la producción, el dato más preciso, es el brote de Newcastle ocurrido en 1960, que dejo grandes pérdidas económicas tras la muerte de 12 millones de aves, considerándose en su momento más del $90 \%$ de esta población en el país, casos similares de enfermedades en el mundo y en la industria avícola se han presentado como: salmonelosis, influenza aviar de alta patogenicidad, Newcastle (velogénico) y leucosis, entre otras (Romero et al., 2009).

De acuerdo a las razones anteriormente expuestas, reviste una gran importancia la capacitación en el diagnóstico oportuno y en la implementación de medidas preventivas que el médico veterinario y zootecnista puede aplicar en cualquier eslabón de la cadena productiva avícola, máxime cuando se maneja una alta densidad poblacional de la especie, donde cualquier error o negligencia cometida, genera pérdidas económicas considerables, que pueden llevar a comprometer la sostenibilidad y rentabilidad de una empresa del sector.

El termino zoonosis viene del griego zoon (animal) y nosos (enfermedad) y fue creado en el siglo XIX por Rudolf Virchow. En 1959, la Organización Mundial de la Salud (OMS) definió las zoonosis como "enfermedades e infecciones transmisibles de un modo natural de los animales vertebrados al hombre y viceversa". Así mismo, hay microorganismos y parásitos que pueden afectar al hombre y que sólo son patógenos para él; por ejemplo, los agentes del sarampión; del mismo modo, hay otros cuya peligrosidad se limita únicamente a una especie o a un número limitado de éstas (peste porcina y bovina, mixomatosis y otras) (Desachy, 2006). Sin embargo, existe otra categoría de agentes patógenos que comprende los que, en condiciones naturales, pueden provocar una enfermedad tanto en el hombre como en un animal, son los agentes de las zoonosis. 
Las enfermedades infecciosas son uno de los principales problemas en la industria avícola representando pérdidas millonarias para los productores (ICA, 2009). trabajo con animales vivos implica ese gran riesgo, ante el cual se deben tomar toda clase de medidas preventivas. En la actualidad los productores avícolas se enfrentan continuamente al reto de asegurar que sus animales, productos y subproductos estén libres de patógenos (GFM y SENASICA, 2010). Entre las medidas más importantes como acción preventiva, dentro de la bioseguridad, están los procesos de limpieza y desinfección de la granja, las cuales al realizarse de manera efectiva en las instalaciones avícolas, aseguran que las enfermedades no se transmitan de una parvada a la siguiente, o de una granja hacia otras.

\section{PREPARACIÓN DE INSTALACIONES}

La limpieza y desinfección de la granja tiene como objeto bajar o disminuir la carga bacteriana de las instalaciones avícolas, disminuyendo en lo posible el riesgo de diseminación de las enfermedades, y con ello se tener un efecto positivo sobre la salud, bienestar y desempeño del desarrollo de las aves (AVIAGEN, 2009). La limpieza se fundamenta en la remoción mecánica de gran parte del material orgánico que alberga la instalación; la desinfección es la eliminación de microorganismos y un desinfectante es un agente o sustancia que al aplicarse a los objetos destruye o inactiva a los microorganismos (GFM y SENASICA, 2010).

El principal objetivo de la limpieza y desinfección es la eliminación de los agentes infecciosos como los virus, bacterias, hongos y parásitos que pueden transmitirse de una parvada hacia el siguiente lote de aves, esto es muy importante ya que si en la parvada anterior se presentó un brote de alguna enfermedad, el agente patógeno puede permanecer durante días, semanas o inclusive meses en cualquier superficie de la granja, principalmente en la pollinaza, pero también en las instalaciones, equipos, utensilios, ropa, alimentos, y en el ambiente que rodea a la granja y otras partes, por lo que los alojamientos avícolas así como sus alrededores deben ser limpiados y desinfectados entre parvadas (AVIAGEN, 2009). El proceso de limpieza y desinfección de los galpones se realiza 
principalmente en tres fases: recolección de pollinaza, limpieza y lavado del galpón, y flameo y desinfección.

Muchas sustancias químicas son capaces de inhibir o eliminar microorganismos, sin embargo no existe un producto que sea capaz de convertirse en el agente químico ideal para el control microbiológico, porque debería cumplir una serie de propiedades que son prácticamente imposibles de reunir en uno solo producto (SSB, 2004). Los desinfectantes intervienen en algunas etapas de la vida microbiana, siendo sus mecanismos de acción complejos, el cual puede ejercerse principalmente sobre una función y comprometiéndose luego otra, algunas veces de manera reversible y otras irreversibles; dentro de los principales mecanismos de acción de los desinfectantes se encuentran:

- Daño de la pared celular que conlleva a la lisis de los microorganismos.

- Alteración de la permeabilidad de la membrana citoplasmática, impidiendo el transporte selectivo de nutrientes al interior de la célula bacteriana.

- Alteración de la naturaleza coloidal del citoplasma, desnaturalizándola o coagulándola.

- Inhibición de la acción enzimática.

- Formación de anti-metabolitos que puede ser tóxicos para el microorganismo.

- Inhibición de la síntesis de ácidos nucleicos.

\section{Recepción de aves}

Una vez que el pollito ha llegado a la unidad de producción, éste deberá ser colocado cerca de la fuente de calor, así como del agua (bebederos de iniciación) y alimento (comederos y/o charolas de iniciación). El equipo que a utilizar en la unidad de producción en la etapa de iniciación (primeras semanas) (comederos y bebederos) deberá ser de fácil limpieza, resistente y durable (AVIAGEN, 2009).

\section{Programas de vacunación}

La inmunización mediante el uso de vacunas inactivadas o vivas modificadas ha sido una herramienta de gran valor para un control efectivo de la enfermedad y 
para disminuir las pérdidas económicas ocasionadas por ella; de esta forma la hiperinmunización de las reproductoras (mediante el uso de vacunas vivas e inactivadas) se ha convertido en una práctica rutinaria, con el fin de transferir adecuados niveles de inmunidad pasiva a la progenie (Cardoso et al., 2000).

Las granjas avícolas se caracterizan por contar con grandes poblaciones alojadas en un mismo galpón, compartiendo las mismas condiciones ambientales y conviviendo en extrema cercanía, esta situación facilita el desequilibrio de la triada epidemiológica y consecuentemente la presentación de enfermedades (AVIAGEN, 2009); por lo tanto, para establecer los programas de vacunación es necesario tener en cuenta:

- Localización de la unidad de producción, cercanía de otras unidades y enfermedades endémicas.

- Presencia de fauna silvestre, puesto que representan un mayor peligro de que alguna enfermedad pueda llegar fácilmente a la parvada (migración = diseminación de enfermedades).

- Tener en cuenta enfermedades de lenta difusión como laringo-traqueitis y viruela aviar, cuando no son prevalentes permiten correr el riesgo de no vacunar rutinariamente, y solo se hace cuando aumenta la probabilidad de presentación, o sobre brote de la enfermedad.

- Conforme aumenta la densidad poblacional, se incrementa la probabilidad de que se presenten diferentes enfermedades y que se difundan más rápidamente.

- A pesar de que es posible obtener respuesta a la mayoría de las vacunas desde un día de edad, cuando se aplican a mayor edad, es mejor la respuesta inmune; además los anticuerpos heredados de las reproductoras interfieren en diferentes grados con la respuesta a la vacunación evitando la reacción del individuo.

- A mayor prevalencia y severidad de una enfermedad se incrementa la necesidad de vacunar a temprana edad; lo ideal es no aplicar vacunas cuando existen estados de estrés por manejo. 
- El programa de vacunación es particular de cada unidad de producción, así como su calendario y variará de acuerdo con el área y entre parvadas, así mismo el programa será determinado por el Médico Veterinario responsable de la unidad de producción.

\section{Técnicas de necropsia}

Esta es una herramienta importante y ayuda como soporte en el proceso de diagnóstico de una enfermedad en un individuo o población animal (Brooks y Munro, 2016). Un estudio post mortem necesita asistirse del laboratorio para poder establecer un diagnóstico etiológico de la causa de la muerte del animal; para obtener resultados confiables es de suma importancia que tanto la toma de muestras como su conservación se realicen de manera correcta, es imprescindible que la muestra sea fresca y de un volumen representativo; en cuanto a las muestras destinadas a microbiología, estas deben ser recolectadas con el mayor grado de asepsia, utilizando frascos o recipientes esterilizados para tal fin, y se deben remitir correctamente rotulados con la información completa del paciente, del Médico Veterinario y las especificaciones claras relativas al tipo de análisis que se requiere, en cuanto a los recipientes para enviar muestras (usualmente de plástico o vidrio) deben empacarse cuidadosamente para evitar su ruptura durante el transporte, cuando es necesaria la refrigeración como en el caso de muestras para pruebas microbiológicas, puede depositarse el frasco con la muestra dentro de un recipiente con hielo teniendo especial cuidado en aislar la muestra del hielo con el objeto de no deteriorar o alterarla, también puede usarse hielo seco, teniendo cuidado de no cerrar herméticamente el recipiente que la contiene para que pueda escaparse el gas y evitar accidentes. Si el animal al que se le tiene que hacer el estudio post mortem se encuentra todavía vivo, puede ser útil tomar algunas muestras como sangre y líquido cefalorraquídeo, antes de la eutanasia (Santander, 2012). 


\section{ENFERMEDADES DE INTERÉS}

Se pretende dar información general de las enfermedades de mayor interés en avicultura sin dejar a un lado los otros agentes etiológicos, estas enfermedades son presentadas por su participación directa en la industria avícola y entre las cuales se encuentran algunas registradas como las de control oficial y reporte a la Organización Mundial de Sanidad Animal (OIE, 2004): Newcastle, Bronquitis Infecciosa, Gumboro, Marek y Micoplasmosis; se pretende con esto relacionar los hallazgos de las necropsias con la literatura disponible, dentro de los puntos a tener en cuenta en cada una de estas enfermedades está: agente etiológico, introducción, epidemiologia y fisiopatología (Nascimento et al., 2005).

\section{Newcastle}

Es una infección altamente contagiosa y con frecuencia severa que existe en todo el mundo y afecta a las aves, incluidas las domésticas; es causada por un virus de la familia de los paramyxovirus. La introducción e implantación primaria del virus en las vías respiratorias, es seguida por su replicación en las células del epitelio mucoso del tracto respiratorio, desde donde alcanza la circulación sanguínea, para un segundo ciclo de replicación en los órganos viscerales y una nueva liberación del virus en la corriente sanguínea, pasando en algunos casos al sistema nervioso central (Figura 1).

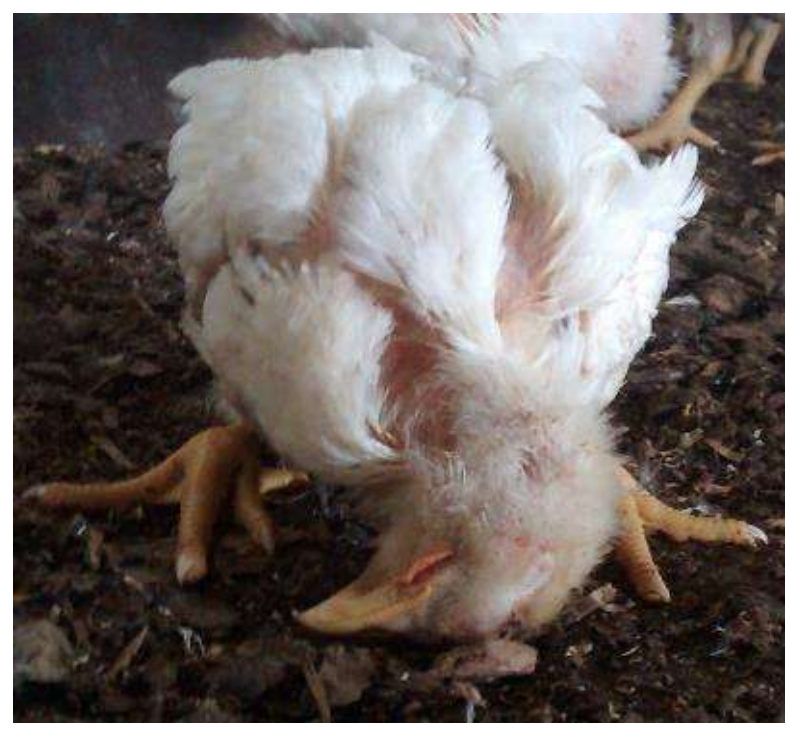

Figura 1. Pollo de dos semanas y media con torticolis y presionando el cráneo contra el suelo; el ave no presentó signos de mioclonos 0 movimientos repetitivos involuntarios. Fuente: Autores. 
Los signos clínicos de la enfermedad de Newcastle incluyen síntomas respiratorios, digestivos y nerviosos, esto dependiendo del tropismo del serovar implicado, pero no por esto, todas las aves con torticolis son positivas a la enfermedad de Newcastle, para esto en la avicultura se realiza una medicina preventiva poblacional, por ejemplo una sola ave con torticolis, en un lote de 20.000 congéneres no es significativo, ni concluyente de enfermedad; al igual que el Paramixovirus algunas enfermedades secundarias por bacterias, también pueden dar signos de torticolis, contaminando el oído medio e interno, produciendo algo similar al síndrome vestibular del perro (Alexander, 2000).

La enfermedad tiene una distribución mundial y afecta principalmente a pollos y pollas productoras de carne y huevo, también afecta pero en menor grado a pavos, faisanes, palomas, codornices, patos, gansos y otras aves silvestres; la forma más importante de transmisión del virus de Newcastle de ave a ave en una parvada, es mediante aerosoles expirados por animales infectados, que a dos días después de la exposición al virus y a un día de mostrar los signos clínicos, empiezan a eliminar el virus durante varios días, como las secreciones nasales contienen altas concentraciones de virus, el agua de bebederos comunales es un medio muy eficaz de transmisión del virus dentro del galpón (Moreno Chan, 1994).

\section{Bronquitis Infecciosa Aviar}

Es causada por el virus coronavirus de la bronquitis infecciosa (IBV), siendo una enfermedad aguda y contagiosa que se caracteriza fundamentalmente por síntomas respiratorios en pollos de engorde mientras que en gallinas se observa a menudo una disminución en postura y calidad del huevo; algunas cepas del virus producen nefritis intersticial y mortalidad; la gravedad de la enfermedad respiratoria inducida por el IBV se ve incrementada por la presencia de patógenos bacterianos, desembocando en aerosaculitis crónica y complicada. El diagnóstico requiere el aislamiento del virus o la demostración del ácido nucleico vírico de los lotes enfermos, puede ser útil la demostración de un aumento de la respuesta de los anticuerpos séricos, pero debe tenerse en cuenta que el uso extendido de vacunas vivas e inactivadas puede complicar tanto la interpretación del 
aislamiento del virus como los hallazgos serológicos; la presencia de cepas antigénicas variables puede anular la inmunidad inducida por la vacunación (Acevedo, 2010).

El curso de la enfermedad en los pollos jóvenes es de 7 a 21 días dependiendo de la severidad de la infección; el virus inicialmente infecta el tracto respiratorio superior, donde está restringido a las células ciliadas y secretoras de mucus, los títulos de virus vivo son máximos en la nariz y tráquea en tres días y permanecen de dos a cinco días, después la infección es comúnmente seguida por infecciones bacterianas secundarias, las cuales pueden ser la principal causa de la enfermedad debilitante, incluyendo la mortalidad (Vandekerchove et al., 2004); además de replicarse en muchos tejidos respiratorios, el virus crece en muchas otras superficies epiteliales, incluyendo riñones, oviducto, testículos y tracto digestivo cloaca (Jackwood y de Wit, 2013).

Algunas cepas del virus son intrínsecamente nefropatogénicas, causando nefritis cuando son inoculadas experimentalmente en pollos libres de patógenos específicos, causando mortalidad (Cook et al., 2001; Li y Yang, 2001); la infección del oviducto se asocia con la disminución en la producción de huevos, el virus puede también replicarse en los testículos (Boltz et al., 2004).

La morbilidad es generalmente alta, $100 \%$ en la mayoría de los casos, pero la mortalidad frecuentemente es baja (5\%), ésta aumenta cuando actúan cepas nefropatógenas (Zanella et al., 2003) o cuando se presenta complicación con agentes patógenos como Escherichia coli, Mycoplasmas y otros virus (Naqi et al., 2001). El virus es altamente infeccioso y se disemina mediante aerosoles, por contacto directo e indirectamente a través de medios mecánicos (equipamiento contaminado, vehículos o materiales del embalaje de los huevos, entre otros elementos), varios serotipos pueden co-circular en una región (Capua et al., 1999).

\section{Enfermedad infecciosa de la bursa de Fabricio o gumboro (EIBF)}

Es considerada una de las patologías de mayor importancia para la avicultura en el mundo debido a las pérdidas económicas que ocasiona no solo en la forma 
clínica con mortalidad sino por su efecto inmunosupresor en pollos menores de tres semanas de edad, siendo su mortalidad directa de $40 \%$ y la morbilidad del $100 \%$ (Babaahmady et al., 2005). Esta enfermedad es producida por un virus de la familia Birna viridae, género Avibirnavirus, siendo el pollo el único hospedador conocido que desarrolla una enfermedad clínica y lesiones definidas como consecuencia de la infección por el virus de la enfermedad de gumboro. La principal vía de infección es la oral a través de la ingestión de heces o material orgánico contaminados.

El virus está presente en los macrófagos y células linfocitarias del yeyuno y ciegos en un periodo de cuatro a cinco días, éste llega al hígado y en cinco horas las células de Kupffer atrapan y fagocitan una cantidad considerable del virus, luego llega al sistema circulatorio principal, llegando a la bolsa de Fabricio, donde los linfocitos $B$ inmaduros son las diana del virus. La enfermedad clínica y muerte ocurre de 64 a 72 horas post-infección; esta enfermedad afecta a pollitos jóvenes y es de prevalencia mundial (Plazas y Peñuela, 2012).

\section{Enfermedad de Marek (EM)}

Es un padecimiento de las aves que se caracteriza por tumores linfoides, parálisis de las patas o de las alas y ocasionalmente de la molleja, se ha confirmado la existencia de este cuadro clínico en diferentes países del mundo, como en Holanda, Estados Unidos y Japón, además de las lesiones descritas se mencionó que en cierto número de los casos también se encontraron tumores linfoides en los ovarios (Toro y Lecompte, 2016).

El virus de la enfermedad de Marek (VEM) pertenece a la familia Herpesviridae, que se subdivide en tres subfamilias: Alphaherpesvirinae, Betaherpesvirinae y Gammaherpesvirinae; su genoma está constituido de ADN y con envoltura y libre de células es muy resistente al ambiente. Para comprender la patogenia de la EM se deben conocer las diferentes maneras de cómo actúa el VEM en el pollo de acuerdo con la fase de la infección y al tipo de interacción entre virus y células en la bolsa de Fabricio, timo, bazo, hígado, nervios y ojo (Morimura et al., 1998); 
después del séptimo día, ocurre un cambio drástico en el tipo de infección, donde cambia de productiva y restrictiva a latente, en esta fase está el antígeno MATSA en bazo, bolsa de Fabricio y timo, además se presenta viremia asociada con células y se sospecha que son las responsables de la diseminación de la infección al resto del organismo (Tsukamoto et al., 1995). La última etapa de infección es de tipo transformante y consiste en la presencia de alteraciones neoplásicas.

La EM en su forma aguda se conoce a la fecha en todo el mundo, especialmente en aquellos países en donde la avicultura se explota en forma intensiva; antes de haberse descubierto la vacuna, la tasa de mortalidad en las parvadas iba del 10 al $30 \%$ y en ocasiones llegaban a alcanzar hasta un $60 \%$. La forma clásica de la enfermedad se caracteriza principalmente por complicaciones nerviosas, la mortalidad no suele superar el $10-15 \%$ y puede durar de unas cuantas semanas a muchos meses. En la forma aguda de la enfermedad, la mortalidad puede aumentar rápidamente en unas cuantas semanas y luego cesar, o puede continuar de modo estabilizado o con un lento descenso durante varios meses; la presentación de linfomas viscerales extendidos es lo más común en la actualidad (Paneque et al., 2014).

\section{Micoplasmosis aviar (MG)}

Se considera esta enfermedad ocasionada por Mycoplasma gallisepticum como una de las enfermedades aviares de mayor impacto económico en las explotaciones de pollos de engorde, ponedoras comerciales y reproductoras, siendo una enfermedad de declaración obligatoria de acuerdo con la organización mundial de sanidad animal (OIE, 2004). La micoplasmosis ocasiona una disminución en producción, calidad e incubabilidad de huevos, incrementándose la tasa de mortalidad embrionaria; lo que exige llegar a una alta selección de pollitos y pollitas de un día de edad en las incubadoras, con el fin de mantener adecuadas características de mejoramiento genético (Nascimento et al., 2005).

En pollos de engorde, se disminuye la ganancia de peso y se incrementa los decomisos en plantas de sacrificio; igualmente se considera que la infección por 
micoplasma facilita la presentación de otras infecciones respiratorias de tipo viral como la enfermedad de Newcastle y la bronquitis infecciosa aviar o de tipo bacteriano, principalmente por E. coli, llevando en muchas ocasiones a la presentación de la enfermedad respiratoria crónica (ERC), del mismo modo, la presencia de micoplasma se ha asociado a complicaciones excesivas y prolongadas en lotes de pollos que presentan alguna infección (Michiels et al., 2016).

Por lo tanto, el objetivo de este trabajo fue aplicar programas preventivos y de manejo sanitario, que incluyeron el diagnostico post-mortem para corregir posibles fallas, en varias fincas dedicadas a la producción de pollos de engorde en el departamento de Cundinamarca, Colombia, esto con el fin de asegurar la calidad e inocuidad de la carne para el consumo humano, mediante la vigilancia de los puntos críticos a lo largo de la cadena de producción.

\section{METODOLOGÍA}

\section{Localización}

Este trabajo se realizó en el departamento de Cundinamarca, la zona de trabajo tiene una humedad relativa anual que oscila entre el 80 y el $85 \%$, la evaporación presenta valores entre 1000 y $1600 \mathrm{~mm}$ anuales, el brillo solar esta entre 1400 y 1700 horas sol durante el año, la temperatura media es $24^{\circ} \mathrm{C}$ alcanzando algunas veces valores superiores a los $30^{\circ} \mathrm{C}$, y la precipitación anual va desde los 1500 a $2500 \mathrm{~mm}$, las 28 producciones avícolas con las cuales se trabajó, que se encontraban principalmente ubicadas en los municipios de Madrid, Bituima, Villeta Albán y Cambao, en las veredas Guatecano, Redil, Moreral, Caturra, Sugamuxi, Praga, Virginia, Vizcaya, San Jorge, San Antonio, Santa Rita, La Lucha, Las Vegas, La Giralda, La Chueca, El Cairo, El Tesoro, El Mango, Delicias, Santuario, Norilandia, La Mancha, Pensilvania, San Felipe, San Sebastián, Doña Alejandra, Santa Cecilia y San Miguel. 


\section{Programas de vacunación}

Durante seis meses se llevó a cabo labores de limpieza y desinfección; en granjas, donde se sacrificaban las aves de 46 a 48 días de edad y para lo cual se destinó un periodo de vacío sanitario de la granja mínimo de 15 días; de acuerdo a los puntos anteriormente expuestos, fue de vital importancia conocer el estatus sanitario de la casa materna para instaurar los protocolos de inmunización animal, y teniendo en cuenta las condiciones de la vacuna, se realizaron los procedimientos dependiendo de las especificaciones del laboratorio. Cada granja tenía una capacidad de tres a cuatro galpones, donde se albergan entre 20.000 a 30.000 aves; para un total aproximado de 500.000 en todas las producciones, con ciclo de vacunación y revacunación de ser necesario.

\section{Recolección de datos y necropsias}

Para esta labor se estableció una tabla en la cual llevó a cabo la recolección de datos, en donde se especifica: el número total de aves muertas por día, edad, hallazgos macroscópicos, granja, entre otros, con el fin de elaborar una tabla de distribución de frecuencias y así poder establecer una relación epidemiológica para cada predio, y de acuerdo a los resultados recomendar un plan de acción para mejorar los programas sanitarios y por tanto su efectividad, y así contribuir al mejoramiento del producto final (Tablas 1 y 2 ).

Tabla 1. Diagnostico porcentual por enfermedad

\begin{tabular}{|c|c|c|c|c|}
\hline \multicolumn{2}{|c|}{ Total de necropsias } & Aspergilosis & Colibacilosis & Micoplasmosis \\
\hline \multirow{5}{*}{$\begin{array}{l}\text { Numero de } \\
\text { necropsias }\end{array}$} & \multirow{5}{*}{1889} & 385 & 385 & 200 \\
\hline & & $20.4 \%$ & $20.4 \%$ & $10.6 \%$ \\
\hline & & Intoxicaciones & Síndrome ascítico & Coccidiosis \\
\hline & & 365 & 1058 & 19 \\
\hline & & $19.3 \%$ & $56.0 \%$ & $1.0 \%$ \\
\hline
\end{tabular}


Tabla 2. Enfermedades presentadas en las granjas evaluadas

\begin{tabular}{|c|c|c|}
\hline Edad (Días) & Lesiones Macroscópicas & $\begin{array}{l}\text { Diagnóstico } \\
\text { presuntivo }\end{array}$ \\
\hline \multirow{3}{*}{4 y 5} & Puntos multifocales blanquecinos en sacos aéreos & Colibacilosis \\
\hline & Puntos multifocales blanquecinos en pulmones & Aspergillosis \\
\hline & Retención saco vitelino & Aspergillosis \\
\hline \multirow{3}{*}{5} & Puntos multifocales blanquecinos en sacos aéreos & Colibacilosis \\
\hline & Retención saco vitelino & Aspergillosis \\
\hline & Puntos multifocales blanquecinos en sacos aéreos & Colibacilosis \\
\hline \multirow[t]{4}{*}{6 y 7} & Puntos multifocales blanquecinos en pulmones & Aspergillosis \\
\hline & Retención saco vitelino & Aspergillosis \\
\hline & Hepatomegalia & Marek \\
\hline & Ictericia Hepática & Miarek \\
\hline \multirow[t]{4}{*}{31} & $\begin{array}{l}\text { Puntos multifocales bancos o negros en parénquima } \\
\text { hepático }\end{array}$ & $\begin{array}{l}\text { Intoxicación } \\
\text { por }\end{array}$ \\
\hline & Bazos de diversos tamaños & aflatoxinas \\
\hline & Acumulo líquido santocrómico & \\
\hline & Intestino congestionado & \\
\hline \multirow[t]{4}{*}{35} & Riñones en forma cerebroide y congestionados & Síndrome \\
\hline & Hipertrofia concéntrica & \\
\hline & Asas intestinales congestionadas & \\
\hline & Puntos multifocales blanquecinos en sacos aéreos & Colibacilosis \\
\hline \multirow[t]{2}{*}{5} & Puntos multifocales blanquecinos en pulmones & Aspergillosis \\
\hline & Retención saco vitelino & Aspergillosis \\
\hline
\end{tabular}

\section{LOGROS Y AVANCES}

\section{Preparaciones instalaciones}

Después de retiradas todas las aves se llevó a cabo una serie de labores que ayudan a reducir en gran medida la carga infecciosa que pudiera haber tenido el lote destinado al sacrificio; las labores realizadas después de la evacuación de las aves con respecto al proceso de desinfección, incluyeron:

- Desalojamiento del total de aves del galpón 
- Retirada de: comederos, mallas metálicas, estibas, y los bebederos automáticos que son elevados (los cuales se retiran después de lavar el galpón con el fin de minimizar lo más posible la salida de algún agente infeccioso que ellos alberguen.

- Retirada la pollinaza, sí esto no se realiza entonces se somete a un proceso de fermentación anaerobia, en el que se apilan montones del material en el centro del galpón con el fin de aumentar la temperatura al interior y dar comienzo al proceso de sanitización del material, este proceso es para reducir microorganismos patógenos hasta un nivel tal que no puedan ocasionar enfermedad (Figuras 2 y 3); una vez apilados los montones en el centro del galpón, se realiza un primer barrido del mismo para así amontonar toda la cama en un solo sitio, y no dejar rastros de pollinaza por todo el galpón.

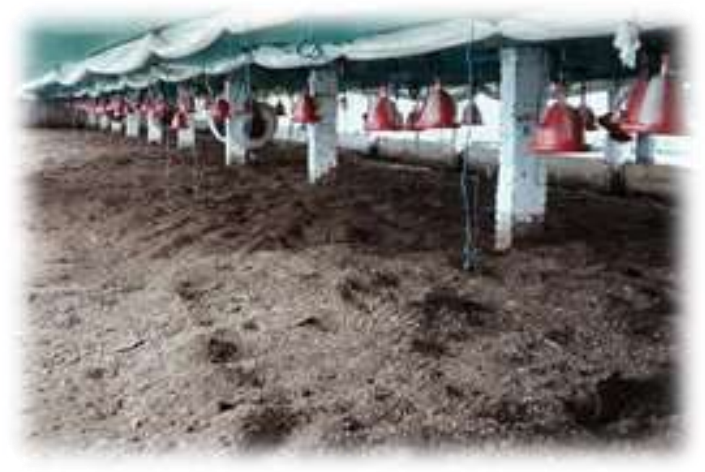

Figura 2. Pollinaza antes de apilar Fuente: Autores

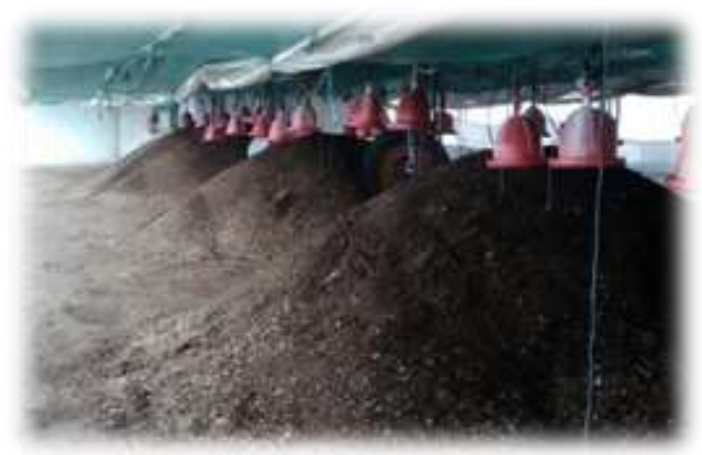

Figura 3. Pollinaza en proceso de sanitización. Fuente: Autores

- Inicio del proceso de lavado, el cual se realiza desde las estructuras más elevadas hacia el piso, pasando por el techo, columnas, paredes, polisombras, plásticos, entre otros; este primer lavado se realiza con dos fines: 1) que el agua utilizada en el lavado también sea usada para humedecer los montones de pollinaza en el centro del galpón, 2) que todo el polvo y algún material orgánico que se haya acumulado en alguna estructura del galpón sea retirado y apilado con la pollinaza.

- Realizar un segundo barrido de todo el galpón para así culminar con la recolección de todo la pollinaza, una vez apilados los montones y 
humedecidos se procede a cubrirlos con plásticos de color negro para no permitir el ingreso de rayos UV y a su vez éste quede hermético.

- Lavar por segunda vez el galpón de la misma manera como se realizó inicialmente, con adición de desinfectantes: formol al 37\%, cloro granulado y yodopovidona, esto con el fin de disminuir la carga microbiana.

- Descubrir la cama reciclada y extenderla por todo el galpón y a su vez se incorporar viruta nueva, colocándola en la parte superior, para luego ser impregnada con un desinfectante con acción acaricida y fúngica; cuando la cama es retirada del galpón únicamente es necesario hacer el proceso de lavado y desinfección de las instalaciones.

\section{Recepción y preparación de círculos para pollitos de un día}

Para esta actividad se tuvo en cuenta los siguientes factores:

- La cama nueva se incorporó, con viruta de madera o cascarilla de arroz, de acuerdo al a disponibilidad de cada predio, con el fin de recibir los pollitos sobre una capa de cama nueva y así protegerlos de algún patógeno residual.

- Se determinó el número de animales por unidad de área, menos de $20^{\circ} \mathrm{C}$ se manejaron 15.5 aves $/ \mathrm{m}^{2}$ y en predios donde se pasó este límite de temperatura se colocaron de 13.5 aves $/ \mathrm{m}^{2}$; una vez dimensionada la cantidad de animales por galpón se procedió a subdividir el área en círculos o encierros iguales o menores a 2700 aves (Figura 4); también fue necesario organizar las cortinas, con el fin de mantener la temperatura adecuada en las primeras tres semanas de edad, éstas se organizaron en dos túneles, el primero divide y delimita cada circulo, y el segundo aísla el círculo del ambiente externo, y por último la cortina externa la cual es la responsable de bloquear las corrientes de aire que puedan dar directamente con el pollito (Figura 5).

- La temperatura de recepción fue en promedio para las diferentes fincas de 30 a $32^{\circ} \mathrm{C}$, esto porque los pollitos de un día de edad no son capaces de regular su temperatura corporal 


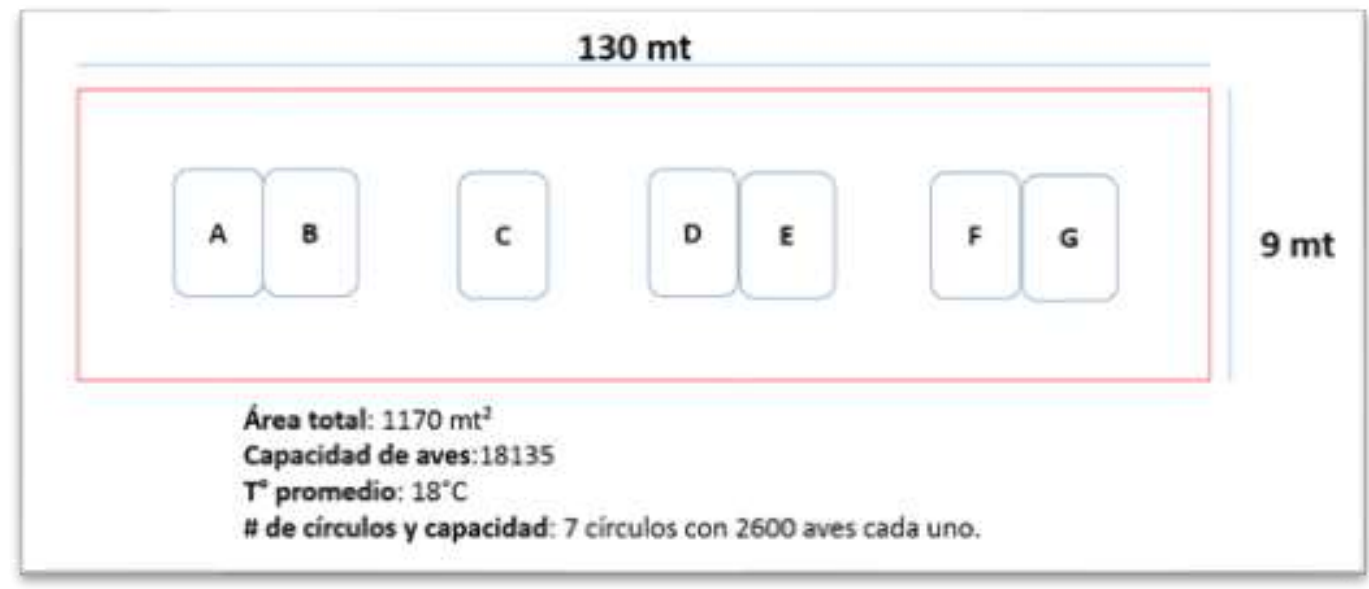

Figura 4. Capacidad de animales por unidad de área

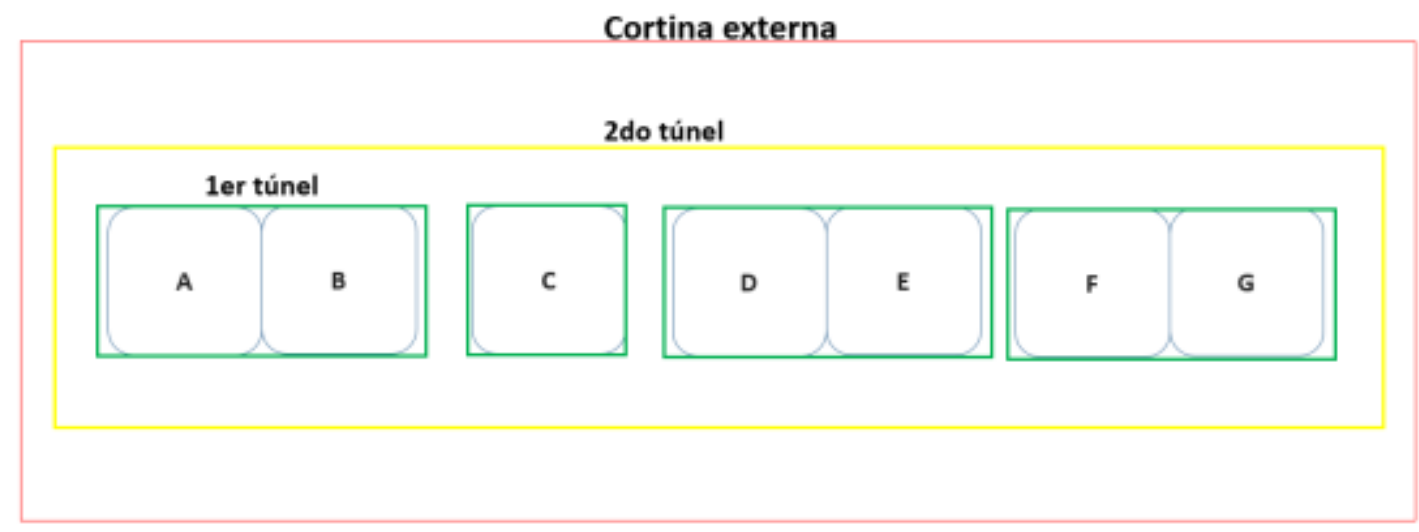

Figura 5. Distribución y organización de túneles y cortinas

- Se utilizó una criadora por cada 1500 pollos, un bebedero y comedero por cada 90 pollos en la primera semana, y en la segunda se redujo el número de aves a cuarenta (Figura 6).

- Las aves de un día de edad llegan a las granjas en tinas o cajas plásticas, las cuales tienen una capacidad de 102, que fueron verificadas contando una a una para así estimar la cantidad de aves encasetadas por ciclo (Figura 7); después del conteo se dispuso a soltarlas dentro del círculo y ponerlas en un ambiente confort para el ave; como se mencionó anteriormente la temperatura debe oscilar entre 30 a $32^{\circ} \mathrm{C}$. 


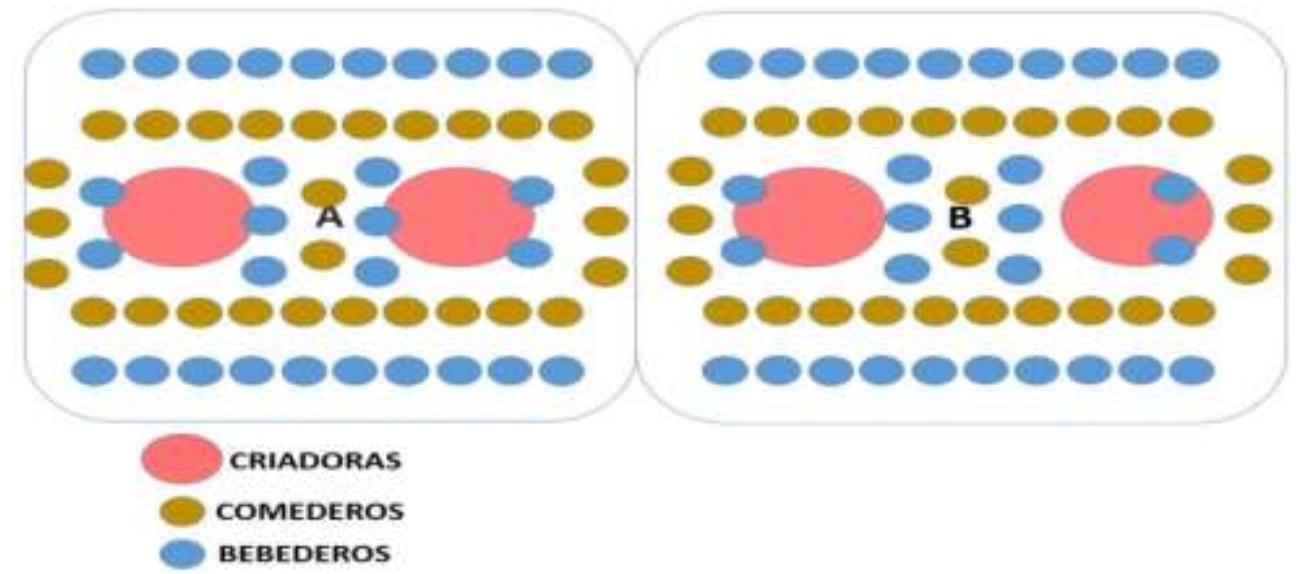

Figura 6. Distribución de comederos, bebedero y criadoras por círculo

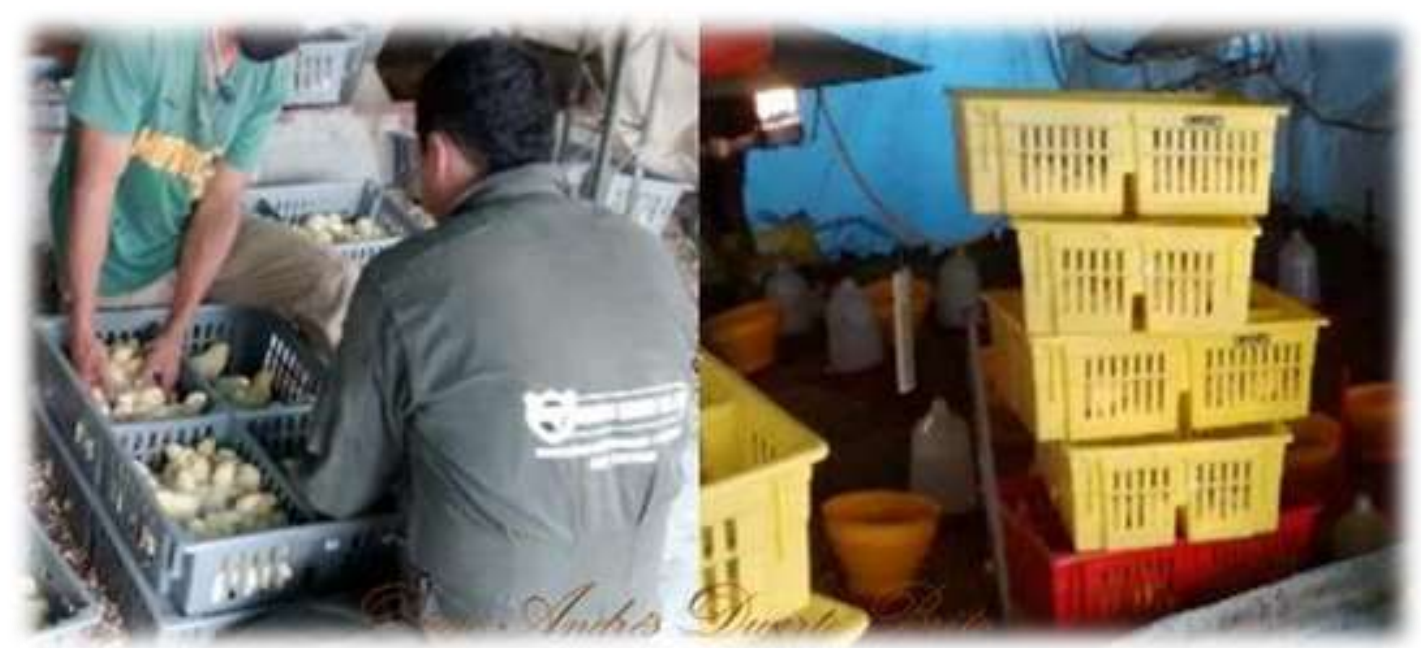

Figura 7. Recepción y conteo de pollitos de un día Fuente: Autores

- Después de suministrar agua y alimentó a los pollitos se instauró un protocolo de antibioticoterapia para contrarrestar a cualquier bacteria oportunista o que haya pasado verticalmente de la madre al pollito, en especial lo concerniente con el Mycoplasma spp; se suministró un antibiótico a base de fluoroquinolonas en el agua de bebida por 5 días.

\section{Plan de vacunación}

La inmunidad pasiva es de suma importancia en la protección de los pollitos que son más susceptibles a patógenos durante las primeras semanas de vida; los 
programas de vacunación realizados se fundamentaron en la casuística epidemiologia de las enfermedades en la zona, cabe resaltar que no todas las granjas son iguales porque existen diferencias tanto ambientales, estructurales y de personal que afectaron dichos planes, por lo tanto, fue necesario aplicar tres programas preventivos (Figura 8).

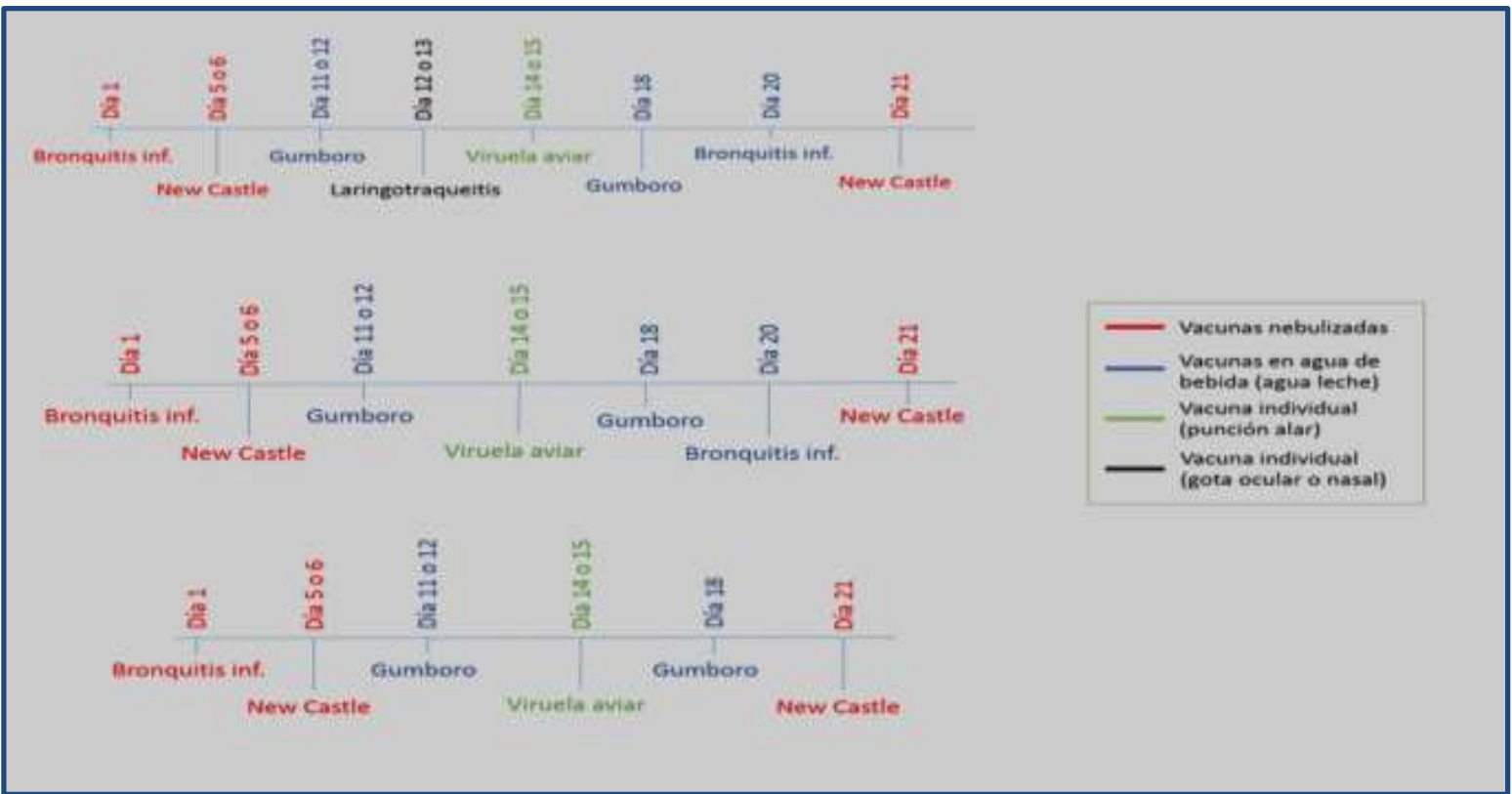

Figura 8. Programas de vacunación aplicados en las granjas productoras de pollos

En general, las vacunas están encaminadas a conferir inmunidad y protección a la parvada, para esto se consideraron métodos que son de fácil adecuación, para facilitar el manejo, por lo tanto se aplicaron las vacunas de tres formas: nebulizadas, en el agua de bebida y vacunación individual; para la primera forma se utilizó un vehículo, agua glicerinada con el fin de darle homogeneidad y grosor a las gotas y así facilitar su adherencia, la segunda se empleó leche y agua como vehículos, la leche utilizada en vacunación debe ser en polvo y descremada, esto con el fin de optimizar la absorción de la vacuna, la tercera manera de aplicación se realizó con la viruela aviar, haciendo punciones alares, en el pliegue superior, de la cara interna del ala, con respecto a la vacuna de laringotraqueitis se recomienda la aplicación ocular o nasal. 


\section{CONCLUSIONES}

Los protocolos de limpieza y desinfección utilizados en las fincas productoras de pollos, se focalizan en dos eventos específicos, el reciclado y compostaje de la cama o su retiro total del galpón, en el primero fue primordial fue la sanitización siendo el punto clave la completa desinfección, reconociendo desinfectantes, dosificaciones, periodo de uso, la concentración y secuencia de los productos es fundamental para disminuir la carga bacteriana.

El personal que labora en esta fincas adquirieron conocimientos en los procedimientos y métodos de vacunación masiva e individual, parámetros y medidas a tener en cuenta al momento de su inmunización, al igual que se reconocieron enfermedades de interés tanto zootécnico como sanitario, por lo tanto se obtuvo experiencia práctica, lo cual conlleva a tener un criterio adecuado al momento de tomar decisiones para solucionar una problemática.

El personal también adquirió habilidades en necropsias, reconociendo partes anatómicas para así compararlas y dar criterios sanitarios en cuanto a hallazgos post-mortem, relacionándolo con patologías que afectan directamente el manejo sanitario de la empresa.

En general, cuando se implementaron estos procesos y métodos de prevención y manejo sanitario de las granjas se obtuvieron beneficios en cuanto a: capacitación de personal, identificación de puntos críticos de contagio, establecimiento de planes de vacunación de acuerdo a cada granja, para lo cual fue importante los resultados de la necropsias (lesiones que solo se conocían en ilustraciones de libro, antes de la capacitación). Todas estas acciones y procedimientos apuntaron a disminuir la intervención de los animales en pie, con el fin de evitar el estrés, disminuyendo un $5 \%$ las necropsias en seis meses.

\section{RECOMENDACIONES}

Al estimar el rendimiento en el empleo de vacunas en los planes sanitarios implementados, se puede establecer costo-beneficio, y si estas actividades 
incrementan la rentabilidad y calidad del producto, además, es importante llevar un monitoreo de aquellas granjas donde se presenta lesiones compatibles con aspergilosis para diagnosticar el origen de esta enfermedad, la cual es la que afecta en mayor grado estas granjas avícolas.

\section{REFERENCIAS BIBLIOGRÁFICAS}

1. Acevedo A.M. Bronquitis infecciosa aviar: diagnóstico y control. REDVET. Revista Electrónica de Veterinaria. 11 (3): 1-23. 2010.

2. Alexander D. Newcastle disease and other avian paramyxoviruses. Revue scientifique et technique (International Office of Epizootics). 19 (2): 443-462. 2000.

3. AVIAGEN, Arbor Acres: guía de manejo de pollo de engorde. Huntsville, USA, Ed: 63 p. 2009.

4. Babaahmady E., Joa R., Noda J. Enfermedad de Gumboro. Histopatología de la Bursa de Fabricio en la enfermedad natural y experimental en pollos de engorde. REDVET. Revista electrónica de Veterinaria. 6 (4). 2005.

5. Boltz D.A., Nakai M., Bahr J.M. Avian infectious bronchitis virus: a possible cause of reduced fertility in the rooster. Avian diseases. 48 (4): 909-915. 2004.

6. Brooks B.H., Munro R. The veterinary forensic necropsy: a review of procedures and protocols. Veterinary pathology. 53 (5): 919-928. 2016.

7. Capua I., Minta Z., Karpinska E., Mawditt K., Britton P., Cavanagh D., Gough R. Co-circulation of four types of infectious bronchitis virus (793/B, 624/I, B1648 and Massachusetts). Avian Pathology. 28 (6): 587-592. 1999.

8. Cardoso T., Rahal P., Pilz D., Teixeira M., Arns C. Replication of classical infectious bursal disease virus in the chicken embryo related cell line. Avian Pathology. 29 (3): 213-217. 2000.

9. Cook J., Chesher J., Baxendale W., Greenwood N., Huggins M., Orbell S. Protection of chickens against renal damage caused by a nephropathogenic infectious bronchitis virus. Avian Pathology. 30 (4): 423-426. 2001.

10. Desachy F. Las zoonosis, transmisión de las enfermedades de los animales al ser humano. Editorial De Vecchi, Barcelona, España. 176 p. 2006.

11. GFM, SENASICA, Gobierno Federal de México; Servicio Nacional de Sanidad Inocuidad y Calidad Agroalimentarias. Manual de buenas prácticas pecuarias en unidades de producción de pollo de engorda. México, Ed: 1aㅡ Ed. 114 p. 2010.

12. ICA, Instituto Colombiano Agropecuario. Resolución 3654 de 2009. Bogotá DC, Colombia, 3 p. 2009.

13. Jackwood M.W., de Wit S. Infectious bronchitis. 2013.

14. Li H., Yang H. Sequence analysis of nephropathogenic infectious bronchitis virus strains of the Massachusetts genotype in Beijing. Avian Pathology. 30 (5): 535541. 2001.

15. Michiels T., Welby S., Vanrobaeys M., Quinet C., Rouffaer L., Lens L., Martel A., Butaye P. Prevalence of Mycoplasma gallisepticum and Mycoplasma synoviae in commercial poultry, racing pigeons and wild birds in Belgium. Avian Pathology. 45 (2): 244-252. 2016.

16. Moreno Chan R. La enfermedad de Newcastle y algunos avances recientes de diagnóstico. Universidad Nacional Autónoma de México Ciudad Universitaria. 
Laboratorio de Microbiología Experimental, Departamento de Virología e Inmunología. p 49-72. 1994.

17. Morimura T., Ohashi K., Sugimoto C., Onuma M. Pathogenesis of Marek's disease (MD) and possible mechanisms of immunity induced by MD vaccine. Journal of Veterinary Medical Science. 60 (1): 1-8. 1998.

18. Naqi S., Thompson G., Bauman B., Mohammed H. The exacerbating effect of infectious bronchitis virus infection on the infectious bursal disease virus-induced suppression of opsonization by Escherichia coli antibody in chickens. Avian diseases. 45 (1): 52-60. 2001.

19. Nascimento E.R., Pereira V., Nascimento M., Barreto M. Avian mycoplasmosis update. Revista Brasileira de Ciência Avícola. 7 (1): 1-9. 2005.

20. OIE, Organización Mundial de Salud Animal. Micoplasmosis aviar (Mycoplasma gallisepticum). En: Manual de las Pruebas de Diagnóstico y de las Vacunas para los Animales Terrestres Paris, Francia, 5ㄹ Ed. p 905-919. 2004.

21. Ortiz M.P., Jiménez L.C. El virus de la influenza aviar H7N9, una nueva variante que afecta seres humanos. Revista Lasallista de Investigación. 10 (2): 164-171. 2013.

22. Paneque M.S., Contreras D.G., Fresneda A., Proenza G., Tabares T.I.B., Diaz E.F. Estudio de protección de la vacuna Labio-Marek frente al desafío con la cepa JM en pollos SPF. Vaccimonitor. 23 (3): 91-99. 2014.

23. Plazas R.A.S., Peñuela L.M.S. Una revisión a las particularidades del sistema respiratorio aviar. Spei Domus. 8 (17): 59-65. 2012.

24. Romero M., Narvaez W., Sánchez J. Enfermedad de Newcastle en aves de traspatio del eje cafetero colombiano. Revista MVZ Córdoba. 14 (2): 1705-1711. 2009.

25. Santander A. Pasantía en diagnostico anatomo-patológico de mamíferos domésticos y animales silvestres en el laboratorio de patología veterinaria, Médico Veterinario y Zootecnista. Facultad de Ciencias Agropecuarias y Recursos Naturales. Programa de Medicina Veterinaria y Zootecnia, Universidad de los Llanos, Villavicencio, Meta, Colombia. 2012.

26. SSB, Secretara de Salud de Bogotá. Uso de desinfectantes; guía para la prevención, control y vigilancia epidemiológica de infecciones intrahospitalarias. Bogotá DC, Colombia, 1ㄹ Ed. 59 p. 2004.

27. Toro P.A.L., Lecompte J.C.R. Virus de la Enfermedad de Marek: aproximación molecular al virus y respuesta inmune del hospedero. CES Medicina Veterinaria y Zootecnia. 11 (3): 71-85. 2016.

28. Tsukamoto K., Tanimura N., Kakita S.-i., Ota K., Mase M., Imai K., Hihara H. Efficacy of three live vaccines against highly virulent infectious bursal disease virus in chickens with or without maternal antibodies. Avian diseases. 39 (2): 218229. 1995.

29. Vandekerchove D., Herdt P.D., Laevens H., Butaye P., Meulemans G., Pasmans F. Significance of interactions between Escherichia coli and respiratory pathogens in layer hen flocks suffering from colibacillosis-associated mortality. Avian Pathology. 33 (3): 298-302. 2004.

30. Zanella A., Lavazza A., Marchi R., Martin A.M., Paganelli F. Avian infectious bronchitis: characterization of new isolates from Italy. Avian diseases. 47 (1): 180185. 2003. 